\title{
Model Predictive Control for the Operation of Building Cooling Systems
}

\author{
Yudong $\mathrm{Ma}^{\star}$, Francesco Borrelli, Brandon Hencey ${ }^{\diamond}$, Brian Coffey** \\ Sorin Bengea ${ }^{\diamond}$ Philip Haves*
}

\begin{abstract}
A model-based predictive control (MPC) is designed for optimal thermal energy storage in building cooling systems. We focus on buildings equipped with a water tank used for actively storing cold water produced by a series of chillers. Typically the chillers are operated at night to recharge the storage tank in order to meet the building demands on the following day. In this paper, we build on our previous work, improve the building load model, and present experimental results. The experiments show that MPC can achieve reduction in the central plant electricity cost and improvement of its efficiency.
\end{abstract}

\section{INTRODUCTION}

The building sector consumes about $40 \%$ of the energy used in the United States and is responsible for nearly $40 \%$ of greenhouse gas emissions [12]. It is therefore economically, socially and environmentally significant to reduce the energy consumption of buildings.

Reductions of $70 \%$ in energy use in buildings are required to achieve the goals for the building sector set by organizations such as the California Public Utilities Commission. Achieving this goal requires the development of highly efficient heating and cooling systems, which are more challenging to control than conventional systems [8], [7], [2].

This work focuses on the modeling and the control of the central plant (thermal energy generation and storage system) at the University of California at Merced in USA. The campus has a significantly enhanced level of instrumentation in order to support the development and demonstration of energy-efficient technologies and practices. It consists of a chiller plant (three chillers redundantly configured as two in series, one backup in parallel), an array of cooling towers, a $7000 \mathrm{~m}^{3}$ chilled water tank, a primary distribution system and secondary distribution loops serving each building of the campus. The two series chillers are operated each night to charge the storage tank to meet campus cooling demand the following day. Although the storage tank enables load shifting to off-peak hours, the lack of an optimized operation results in conservatively over-charging the tank.

A simplified model of the central plant and a MPC strategy has been presented and discussed in [10]. The work in [10]

* Y. Ma, F. Borrelli are with the Department of Mechanical Engineering, University of California, Berkeley, CA 94720-1740, USA. E-mail: \{myd07, fborrelli\}@berkeley.edu.

$\diamond$ B. Hencey and S. Bengea are with United Technologies Research Center, East Hartford, Connecticut, USA. Email: \{HenceyBM, Bengeasc\}@utrc.utc.com.

* P. Haves is with Lawrence Berkeley National Lab, USA. Email: phaves@lbl.gov.

** B. Coffey is with the Department of Architecture, University of California, Berkeley, CA 94720-1740, USA. Email: bcoffey@berkeley.edu. uses an oversimplified campus load model and presents simulation results. In this paper a more detailed campus load model is developed and validated with measured historical data. Moreover experimental results with the MPC scheme are reported.

Although this paper focuses on the specific architecture of the UC Merced Campus, the main ideas and methodologies can be applied to a wider class of building systems which use thermal energy storage. In particular the contributions of this paper and our previous work [10] include: $(i)$ the development of a simple, yet descriptive nonlinear model of the overall cooling system, (ii) the development of a MPC scheme for minimizing energy consumption, (iii) the presentation of experimental results showing a reduction of electricity bill compared to currently adopted policies, and improvement of the overall system performance.

We remark that the evaluation of optimal controllers for active and passive building thermal storage has been studied in the past by several authors (see [4], [9], [6], [5] and references therein). In particular in [4] the authors investigate a three-story office building equipped with two chillers with constant coefficient of performance and a thermal energy storage system. An optimal controller is designed in order to compute the cooling capacity produced by the two chillers without accounting for pump power. Experimental results are presented in [9] where the optimal controller is implemented in a receding horizon fashion on an unoccupied test bed.

The paper is organized as follows. Section II introduces the general system, presents a more detailed campus load model and a fan coil model. In section III the MPC control algorithm is outlined. Experimental setups and results are presented in section IV and section V respectively. Finally, conclusions are drawn in section VI.

\section{SYSTEM MODEL}

In this section we describe the main components of the central plant used to generate and store thermal energy. UC Merced campus has been built with a vision to create living laboratories for energy research. In this paper we focus on the higher level control systems which actuate two electric chillers that are operated at night to take advantage of nighttime electricity rates and lower ambient temperature to fill up a $7000 \mathrm{~m}^{3}$ tank of chilled water. The following day, the chilled water is pumped from the tank to cool down the campus. The main scheme of the cooling system at UC Merced is detailed in [10].

The following subsections present a dynamic model of the system. Our objective is to develop a simplified yet descrip- 
tive model which can be used for real time optimization in a MPC scheme.

\section{A. Nomenclature}

The variables, parameters and subscripts listed in table I-II will be used in this paper.

\begin{tabular}{cl}
\hline parameters and variables & description \\
\hline$t:$ & time \\
$\dot{Q}:$ & heat flow transferred from one \\
$\dot{m}:$ & medium to another $[\mathrm{W}]$ \\
$T:$ & mass flow rate $[\mathrm{kg} / \mathrm{s}]$ \\
$R:$ & Temperature $[\mathrm{K}]$ \\
$C:$ & heat resistor $[\mathrm{K} / \mathrm{W}]$ \\
$S:$ & heat capacitor $[\mathrm{J} / \mathrm{K}]$ \\
$R_{u}:$ & Weight on the energy consumption \\
$H_{p}:$ & Length of prediction horizon \\
$H_{u}:$ & Length of control horizon \\
\hline
\end{tabular}

TABLE I: Parameters and variables

\section{B. Main subsystems of the cooling system}

The model developed in [10] has four components: the chillers and cooling towers, the thermal storage tank, the campus model and the electricity energy price. In this work we use the same models as in [10] with the exception of the campus model. The campus model consists of a load model and a fan coil model. The load model predicts the total energy required to cool the campus based on the information of date, time, occupancy and weather. The coil model captures the heat exchange between chilled water and the air in the campus buildings. Weather predictions are downloaded from the internet and used for campus load prediction. Details are presented in the next sections.

1) Campus Load Model: The campus load model has two subcomponents: "the Solar and Internal Load Predictor" and the "Building Thermal Load Predictor" (see figure 1).

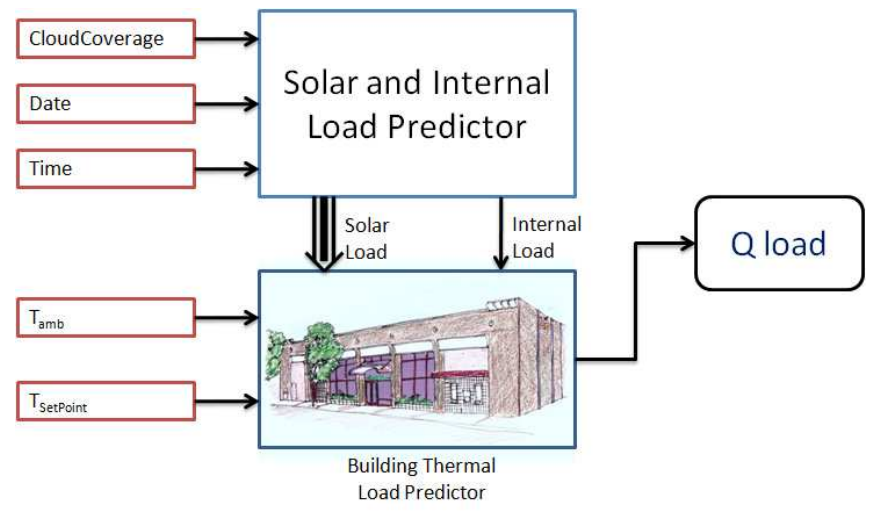

Fig. 1: Campus Load Model

a) Solar and Internal Load Predictor: The Solar and Internal Load Predictor uses time $\left(t_{t d}\right.$ [sec], a number ranging from 0 to 86400), date ( $t_{d y}$, a number between 1 to $365(366) ; t_{d w}$, a number between 1 to 7 ) and cloud coverage ( $\beta_{\text {cloud }}$, a continuous value from 0 to 1 , reflecting the impacts of cloud on the solar energy) as its inputs and calculates

\begin{tabular}{|c|c|}
\hline subscriptions & description \\
\hline air: & air \\
\hline 'cmp: & campus \\
\hline$\cdot c m p, r:$ & campus return \\
\hline$c m p, s:$ & campus supply \\
\hline C $C H W S$ : & chilled water supplied from the chillers \\
\hline$\cdot C H W R$ : & chilled water returning to the chillers \\
\hline$\cdot a m b$ : & ambient \\
\hline real: & data collected from real measurement \\
\hline$r_{i n}:$ & inside \\
\hline out: & outside \\
\hline ref: & reference \\
\hline$\cdot s p:$ & set points \\
\hline
\end{tabular}

TABLE II: Subscripts

inside and outside solar loads and internal load. The outside solar load reflects the solar energy on the outer surface of the building, while the inside solar load is the solar radiation into the building (e.g. sunshine through the windows into rooms). The internal load includes the heat from people, lights and equipment. The outside and inside solar loads are calculated as follows:

$$
\begin{aligned}
S_{\text {Hour }} & =\left(t_{t d}-12\right) \times 15^{\circ} \\
S_{\text {Dec }} & =-23.45^{\circ} \times \cos \left(360^{\circ} \frac{t_{d y}+10}{365}\right) \\
E_{\text {Solar }} & =\max \left(0, \cos \left(S_{\text {Hour }}\right) \cos \left(S_{\text {Dec }}\right) \cos (\text { Latitude })\right. \\
& \left.+\sin \left(S_{\text {Dec }}\right) \sin (\text { Latitude })\right) \\
\dot{Q}_{\text {Solar }, \text { in }} & =\beta_{\text {cloud }} E_{\text {Solar }} \theta_{\text {in }} \\
\dot{Q}_{\text {Solar }, \text { out }} & =\beta_{\text {cloud }} E_{\text {Solar }} \theta_{\text {out }}
\end{aligned}
$$

where $S_{H o u r}$ and $S_{D e c}$ are variables calculated based on time and date to indicate the solar projection angle, $E_{S o l a r}$ is the extraterrestrial horizontal radiation, $\theta_{\text {in }}\left(\theta_{\text {out }}\right)$ is the solar load on the inner (outer) wall mass per unit of clearsky extraterrestrial horizontal radiation and it depends on the building geometry. The internal load is assumed to be a piecewise constant signal with a period of one week, and it is evaluated as:

$$
\begin{array}{r}
\gamma=\left\{\begin{array}{lll}
1 & \text { if } t_{\text {start }} \leq t_{t d} \leq t_{\text {end }} \\
0 & \text { Otherwise }
\end{array}\right. \\
\dot{Q}_{\text {internal }}= \begin{cases}\gamma \dot{Q}_{\text {Saturday }} & \text { if } t_{d w}=6 \\
\gamma \dot{Q}_{\text {Sunday }} & \text { if } t_{d w}=7 \\
\gamma \dot{Q}_{\text {Weekday }} & \text { Otherwise }\end{cases}
\end{array}
$$

where $t_{\text {start }}$ and $t_{\text {end }}$ indicate the time interval when the internal load is different from zero. $\dot{Q}_{\text {Saturday }}, \dot{Q}_{\text {Sunday }}$ and $\dot{Q}_{W e e k d a y}$ are constant internal load values during different days of the week.

b) Building Thermal Load Predictor: The Building Thermal Load Predictor predicts the cooling load of buildings whose main components includes walls and windows which are conventionally modeled by using thermal resistances and thermal capacitors [3]. The proposed campus thermal load model is sketched in figure 2. $R_{1}$ represents the thermal resistance of windows. The wall is separated into two layers, where $C_{i n}$ and $C_{\text {out }}$ capture the heat capacity of the wall when influenced by outside and inside solar 
load, respectively. The heat resistance between $C_{i n}$ and $C_{\text {out }}$ is modeled by $R_{3}$ while $R_{2}$ and $R_{4}$ capture the heat resistance caused by heat convection. The interconnection of the thermal components is shown in figure 2. The model inputs are ambient temperature $\left(T_{a m b}\right)$, outside solar load $\left(\dot{Q}_{\text {Solar }, \text { out }}\right)$, inside solar load $\left(\dot{Q}_{\text {Solar,in }}\right)$, internal load $\left(Q_{\text {internal }}\right)$ and the indoor temperature set-point $\left(T_{\text {setpoint }}\right)$. The model internal states are the temperatures of the thermal masses $\left(T_{i n}, T_{\text {out }}\right)$ and the model output is the cooling load $\left(\dot{Q}_{\text {Load }}\right)$.

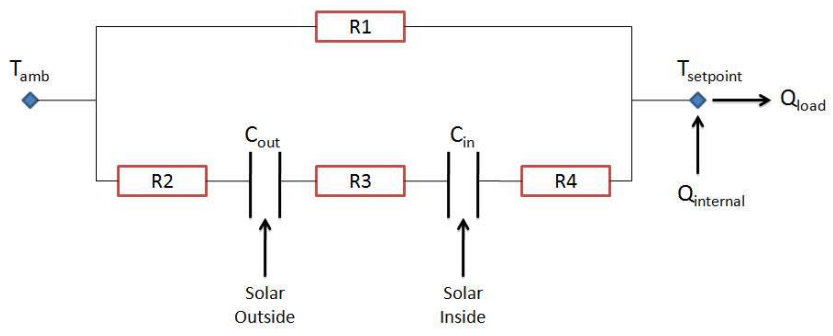

Fig. 2: Building Thermal Load Model

The detailed equations describing the model are:

$$
\begin{aligned}
& \dot{Q}_{\text {Load }}=\max \left(0, \dot{Q}_{\text {internal }}+\frac{T_{i n}-T_{\text {air }}}{R_{4}}+\frac{T_{a m b}-T_{s p}}{R_{1}}\right) \\
& \dot{T}_{\text {in }}=\frac{\dot{Q}_{\text {Solar }, \text { in }}+\frac{T_{o u t}-T_{i n}}{R_{3}}+\frac{T_{s p}-T_{i n}}{R_{4}}}{C_{i n}} \\
& \dot{T}_{\text {out }}=\frac{\dot{Q}_{\text {Solar }, \text { out }}+\frac{T_{a m b}-T_{\text {out }}}{R_{2}}+\frac{T_{i n}-T_{\text {out }}}{R_{3}}}{C_{\text {out }}}
\end{aligned}
$$

The campus load model is described as a thermodynamic system by collecting equation (1)-(10).

The model can be compacted as:

$$
\begin{aligned}
T_{\text {state }} & =\left[T_{\text {in }} ; T_{\text {out }}\right] \\
\Phi & =\left[t_{t d} ; t_{d y} ; t_{d w} ; \beta_{\text {cloud }} ; T_{\text {amb }} ; T_{\text {setpoint }} ; T_{\text {air }}\right] \\
\dot{T}_{\text {state }} & =g\left(T_{\text {state }}, \Phi\right) \\
\dot{Q}_{\text {Load }} & =L O A D\left(T_{\text {state }}, \Phi\right)
\end{aligned}
$$

The parameters used in model (11) are summarized in table III. These parameters are identified by using historical data collected in 2008, and minimizing the root mean square of the error between the model output and the measured load of the campus. The identified set of parameters are listed in table IV.

Figure 3 shows the identification result. The proposed campus load model captures the main load dynamics in May 2009. However, the peak values are not well modeled during the high load sessions and the campus load is slightly overpredicted by the model for low load period of time. This can be improved by using a different set of parameters for different level of building load.

The identified campus load model is validated by using load measurements from Jun 01st to Jun 05th, 2009. Figure 4 presents the validation results. The measured campus load is depicted as the dotted line, and the solid line shows the

\begin{tabular}{ll}
\hline Optimized Parameter & Description \\
\hline$t_{\text {start }}$ & starting time of the internal load \\
$t_{\text {end }}$ & ending time of the internal load \\
$\dot{Q}_{\text {Saturday }}$ & internal load for Saturdays \\
$\dot{Q}_{\text {Sunday }}$ & internal load for Sundays \\
$\dot{Q}_{\text {Weekday }}$ & internal load for Weekdays \\
$\theta_{\text {in }}$ & inside solar gain related to building \\
& geometry \\
$\theta_{\text {out }}$ & outside solar gain related to building \\
& geometry \\
$R_{1}-R_{4}$ & thermal resistors in Building Thermal \\
& Load component \\
$C_{\text {out }}, C_{\text {in }}$ & thermal capacitors in Building Thermal \\
& Load component \\
\hline
\end{tabular}

TABLE III: Tuning parameters of the building load model

\begin{tabular}{llll}
\hline Parameter & values & Parameter & values \\
\hline$t_{\text {start }}$ & 6 & $\theta_{\text {out }}$ & 6.25 \\
$t_{\text {end }}$ & 20 & $R_{1}$ & 8069.8125 \\
$\dot{Q}_{\text {Saturday }}$ & 154180 & $R_{2}$ & 37870 \\
$\dot{Q}_{\text {Sunday }}$ & 154178.25 & $R_{3}$ & 10135 \\
$\dot{Q}_{\text {Weekday }}$ & 154258 & $R_{4}$ & 161313 \\
$\theta_{\text {in }}$ & 6.25 & $C_{\text {out }}$ & 221630.42 \\
$C_{\text {in }}$ & 398005.88 & & \\
\hline
\end{tabular}

TABLE IV: Identified parameters of the campus load model

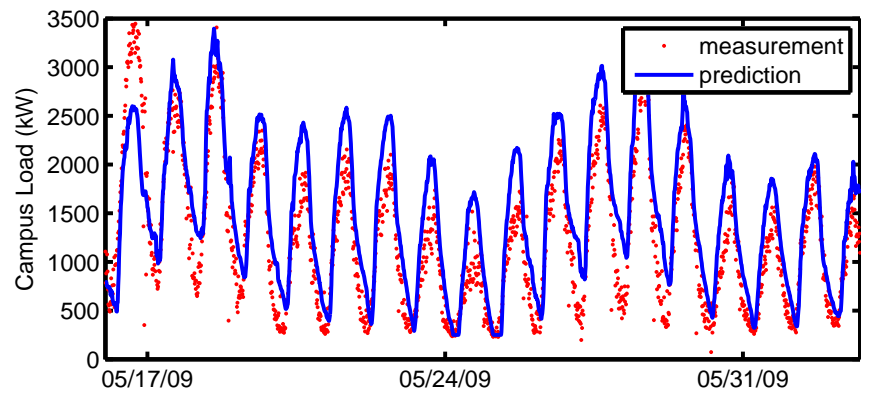

Fig. 3: Campus load model validation (measured data dots in red and simulation output in blue line)

campus load prediction by the proposed campus load model. Clearly, the load dynamics are successfully captured by the proposed model.

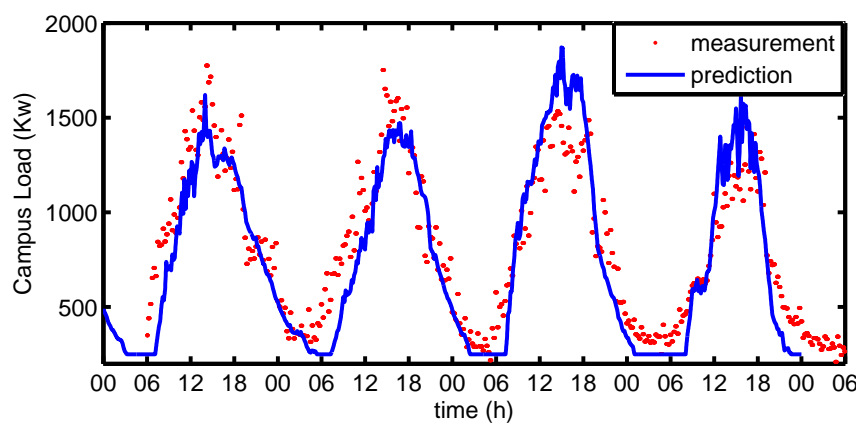

Fig. 4: Campus load validation

2) Fan Coil Model: The fan coil models the heat exchange between the chiller water supplied to the campus and air in the buildings. Several fan coil models are available in the literature. In this work we used the simplified model 
presented in [1] where the model inputs are the cooling load $\left(\dot{Q}_{\text {Load }}\right)$ calculated from campus load model described in II-B.1, water supply temperature $\left(T_{c m p, s}\right)$ and ambient temperature $\left(T_{a m b}\right)$. The model outputs are water mass flow rate supplied to the campus $\left(\dot{m}_{c m p, s}\right)$ and the return water temperature from the campus $\left(T_{c m p, r}\right)$. The resulting semiempirical model [1] can be compactly represented by using the following implicit function:

$$
\text { FanCoil }\left(\dot{Q}_{\text {Load }}, T_{c m p, s}, T_{a m b}, \dot{m}_{c m p, s}, T_{c m p, r}\right)=0
$$

The fan coil model is implemented as a look up table $(2000 \times 18 \times 60)$ to avoid solving implicit equations which are computational prohibitive for online optimization. We grid over the input space of the model $\left[\dot{Q}_{L o a d} ; T_{c m p, s} ; T_{a m b}\right]$ and compute the corresponding outputs $\left[\dot{m}_{c m p, s} ; T_{c m p, r}\right]$ by solving equation (12).

3) Weather Predictions: The weather predictions are downloaded from the web http://www. weather.gov. The weather data includes temperature and humidity for the following 3 days with a sampling time of 2 hours. The predicted weather information is used to predict the campus load.

\section{Control Variables}

1) $T_{C W S, r e f}$ : Reference temperature of the water exiting the cooling tower.

2) $\dot{m}_{C H W S, r e f}$ : Mass flow rate of the chiller water supply. It is a disconnected set. The mass flow rate is 0 when chiller is off, and $[148,235] \mathrm{kg} / \mathrm{s}$ while the chiller is operating.

3) $T_{C H W S, r e f}$ : Reference temperature of the water flowing out of the chiller.

\section{Measured Variables}

1) $T_{C H W R}$ : Temperature of the water return to the chiller.

2) $T_{a}$ : Temperature of the cool water in the tank.

3) $T_{b}$ : Temperature of the warm water in the tank.

4) $z_{a}$ : Height of warm tank water above the thermocline.

5) $z_{b}$ : Height of cool tank water below the thermocline.

\section{E. Operation Constraints}

The following constraints avoid the malfunction of the system components.

1) $T_{C W S, r e f} \in[288,295] \mathrm{K}$.

2) $\dot{m}_{C H W S, r e f} \in\{0\} \bigcup[148,235] \mathrm{kg} / \mathrm{s}$.

3) $T_{C H W S, r e f} \in[276.5,280.4] \mathrm{K}$.

4) $T_{C H W R} \in[283,295] K$.

5) $z_{b} \in[0.3,1] z_{\text {tank }}$.

\section{F. Model Summary}

The model consists of the chillers and cooling towers, the thermal storage tank and the electricity energy prices introduced in [10], the campus load model described in section II-B.1, and the fan coil model in section II-B.2. The model can be summarized as:

$$
\begin{aligned}
& x(t+1)=f(x(t), u(t), \Phi(t), t) \\
& y(t)=g(x(t), u(t), \Phi(t), t) ;
\end{aligned}
$$

where

$$
\begin{aligned}
& f=\left\{\begin{array}{l}
f_{1}(x(t), u(t), \Phi(t), t) ; \quad \text { if } \dot{m}_{C H W S} \leq \dot{m}_{c m p} \\
f_{2}(x(t), u(t), \Phi(t), t) ; \quad \text { if } \dot{m}_{C H W S}>\dot{m}_{c m p}
\end{array}\right. \\
& u(t)=\left[T_{C W S, r e f} ; \dot{m}_{C H W S} ; T_{C H W S, r e f}\right] \in \mathbb{U} \\
& x(t)=\left[U_{a} ; U_{b} ; z_{a} ; z_{b} ; T_{i n} ; T_{\text {out }}\right] \\
& y(t)=\left[T_{C H W R} ; z_{b}\right] \in \mathbb{Y} .
\end{aligned}
$$

$\mathbb{U}$ is the feasible control input set defined in section II-E; $\mathbb{Y}$ is the feasible output set defined in section II-E.

\section{MPC PROBLEM FORMULATION}

We refer to [10] for the detailed MPC design procedure. The objective of the optimal controller is to find the optimal control sequence so that we can satisfy the required cooling load while minimizing the electricity costs. Let $U_{0 \rightarrow N-1 \mid t}^{\star}=\left\{u_{0 \mid t}^{\star}, \cdots, u_{N-1 \mid t}^{\star}\right\}$ be the optimal solution of such optimization problem at time $t$. Then, the first element of $U_{0 \rightarrow N-1 \mid t}^{\star}$ is implemented to the system $\left(u(t)=u_{0 \mid t}^{\star}\right)$.

The optimization problem is repeated at time $t+1$, based on the new state $x_{t+1 \mid t+1}=x(t+1)$, yielding a moving or receding horizon control strategy. The proposed MPC controller uses a move blocking strategy to reduce the computational time required for its real time implementation. Furthermore, terminal constraints are imposed to guarantee the persistent feasibility of the MPC. The technical details can be found in [10], [11]. The control sampling time is one hour, and prediction horizon is set to $24 \mathrm{~h}$ (one day).

\section{EXPERIMENTAL SETUP}

The MPC controller outlined in section III has been implemented at UC Merced. The detailed experimental setup is described below. The MPC controller computes the set points for the chillers and cooling towers at the central plant. Because of lower level control loops, the closed loop system indirectly affects all the components of the campus including the pumps and fan coils of the distribution system. The MPC algorithm is implemented in Matlab ${ }^{\circledR}$ and running in real-time on a Pentium 4 Intel $^{\circledR}$ processor. The MPC algorithm receives and sends data to the campus through the Automated Logics Web Control (ALC) system. ALC is a building automation system, offering a user interface and some control features. ALC enables one to access all building management functions including (1) set and change schedules; (2) adjust setpoints and other control parameters; (3) trend building conditions; (4) view and acknowledge alarms and events; (5) run preconfigured and customized reports on energy usage, occupant overrides, tenant billing.

\section{EXPERIMENTAL RESULTS}

Three types of scenarios have been studied in order to evaluate the performance of the controller:

[S1] Scenario 1 is the baseline performance. The plant is operated manually by using the policy defined by the plant managers. There is no optimal control algorithm involved. Rather, the control policy is based on the operators' experience. The data for experiment $\mathrm{S} 1$ are collected from May 27th to May 31st, 2009. 
[S2] Scenario 2 implements the MPC control in section III. The data for experiment S2 are collected from June 2nd to June 6th 2009.

[S3] In Scenario 3 the plant is operated manually by using a modified policy defined by the plant managers. The modifications are extracted by observing the policy used by the MPC controller in S2. The data for experiment S3 are collected from June 8th to June 12th, 2009.

\section{A. Comparison Metrics}

Two comparison metrics are defined to evaluate the performance of MPC: the electricity bills and the coefficient of performance.

a) Electricity Bill: The electricity bill

$$
\text { Bill }=\sum_{k=0}^{N} C(k \Delta t) \operatorname{Power}(x(k \Delta t), u((k-1) \Delta t)) \Delta t
$$

is the cost function that the proposed MPC controller minimizes. Power $(x, u)$ is the electrical power consumption as a function of states and inputs, and $C(t)$ is the price of electricity at time $t$. Both are defined in [10]. By comparing the electricity bill we can quantify the cost savings generated by the MPC controller.

b) Coefficient of Performance: The Coefficient of Performance (COP)

$$
C O P=E_{\text {Generated }}^{\text {Thermal }} / E_{\text {plant }}^{\text {Electrical }}
$$

captures the efficiency of the central plant, i.e., the amount of thermal energy $(\mathrm{J})$ generated by the central plant with $1 \mathrm{~J}$ of electrical energy. $E_{\text {plant }}^{\text {Electrical }}$ is the electrical energy consumed by the central plant, and $E_{\text {Generated }}^{\text {Thermal }}$ is the thermal energy generated by the central plant defined as

$$
\begin{gathered}
E_{\text {Generated }}^{\text {Thermal }}=\sum_{k=0}^{N} \dot{m}_{C H W S}(k \Delta t)\left(T_{C H W R}(k \Delta t)\right. \\
\left.-T_{C H W S}(k \Delta t)\right) \Delta t
\end{gathered}
$$

By comparing the COP between the three scenarios S1, S2, and S3, we can better understand if MPC improves the efficiency of the central plant.

\section{B. Discussion of Experimental Results}

Next we compare the three experiments S1, S2 and S3 by analyzing the performance of the central plant and the corresponding control profiles.

1) Performance Comparison: The performance of the central plant will be compared by using the metrics defined in section V-A. Table V lists the electrical energy consumption,

\begin{tabular}{lccc}
\hline & S1 & S2 & S3 \\
\hline Energy Consumption (Electrical) $\left[10^{6} \mathrm{KJ}\right]$ & 8.63 & 4.25 & 4.40 \\
Energy Generated (Thermal) $\left[10^{7} \mathrm{KJ}\right]$ & 4.05 & 2.01 & 2.31 \\
COP & 4.70 & 4.77 & 5.26 \\
Bill [dollar] & 1680 & 418 & 475 \\
\hline
\end{tabular}

TABLE V: Central plant performance comparison (all quantities correspond to daily average)

thermal energy generated, COP and the electricity bill for experiments S1, S2 and S3. We can observe that: i) comparing S1 with S2. The MPC controller has significantly reduced the daily electricity bill in experiment $\mathrm{S} 2$ by $\$ 1265$ compared to experiment S1. Meantime, the efficiency of central plant, COP, is also improved by $1.5 \%$, ii) comparing S3 with S1.The electricity bill reduction is $\$ 1205$ and COP is increased by $11.9 \%$.

The performance improvement is further discussed by looking at the implemented control profiles in the rest of the section.

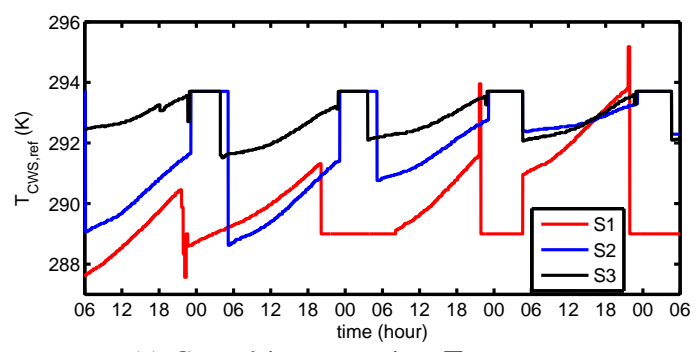

(a) Control input setpoints $T_{C W S, r e f}$

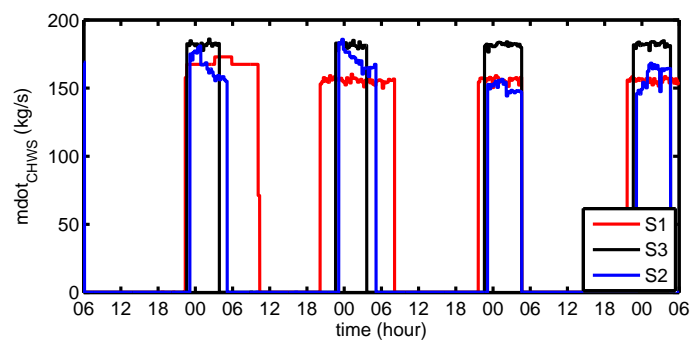

(b) Control input setpoints $\dot{m}_{C H W S, r e f}$

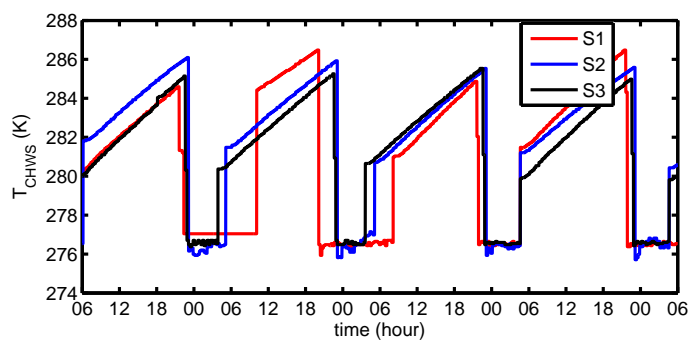

(c) Control input setpoints $T_{C H W S, r e f}$

Fig. 5: Control Sequence Set points (Set points are valid only during the charging period of time)

\begin{tabular}{lccc}
\hline & $\mathrm{S} 1$ & $\mathrm{~S} 2$ & $\mathrm{~S} 3$ \\
\hline$T_{C W S}[\mathrm{~K}]$ & 289.0 & 292.3 & 293.2 \\
$\dot{m}_{C H W S}[\mathrm{Kg} / \mathrm{s}][\mathrm{KJ}]$ & 152.6 & 158.2 & 178.0 \\
$T_{C H W S}[\mathrm{~K}]$ & 276.7 & 276.4 & 276.9 \\
\hline
\end{tabular}

TABLE VI: Average values of central plant flows and temperatures during charging time

2) Control Profile: Figure (5) shows the control profiles for experiments S1, S2 and S3 respectively. Table VI lists the average values of the control set points during the charging time. Based on these information the following remarks can be drawn:

- The MPC controller in S2 uses higher condensed water supply temperature set points $\left(T_{C W S, r e f}\right)$ for cooling towers than experiment S1. In the baseline control (experiment S1), the operators usually set the $T_{C W S \text {, ref }}$ as low as possible so that the cooling towers always work 
at full load. However, it turns out the cooling towers are overloaded, which means higher $T_{C W S \text {,ref }}$ can also guarantee the functionality of the cooling towers while consuming less energy.

- During experiment S2, the central plant is working with shorter charging windows, and the average mass flow rate $\dot{m}_{C H W S}$ is greater than that in $\mathrm{S} 1$.

- The set points of chilled water supply temperature $T_{C H W S, r e f}$ for S1, S2 and S3 are reported in figure $(5(\mathrm{c}))$, and for all three scenarios, there is no noticeable difference.

- The level of the tank cool water is brought to $90 \%$ at the end of each charging event in both experiments S2 and S3, while it is brought to $100 \%$ and overcharged in experiment $\mathrm{S} 1$.

We notice that experiment $\mathrm{S} 3$ improves COP over experiment S2 (with MPC in the loop). The reason is that the MPC in S2 assumes the start time and stop time of the central plant can only be multiple of the sampling time (one hour). As a result a constant and high mass flow rate would overcharge the tank. As it can be observed in figure 5, the mass flow rate $\left(\dot{m}_{C H W S, r e f}\right)$ in experiment $\mathbf{S} 2$ is high only at the beginning of the charging window. Then, it decreases in order to satisfy the load demand. Since for the specific scenario and chillers performance curves, a high COP is always obtained for higher mass flow rates $\left(\dot{m}_{C H W S, r e f}\right)$, the decrease in $\dot{m}_{C H W S, r e f}$ erodes the efficiency of the central plant. Decreasing the control sampling can address this problem.

After experiment $\mathrm{S} 2$ the operators observed the behavior of the MPC and decided to apply maximum chilled water supply mass flow rate, not fully charge the tank everyday, and set the condensed water supply temperature around 293.7K. These modification are used in scenario S3. As observed from table VI, the performance of the central plant, in terms of COP, is improved by $11.9 \%$ compared to their original baseline control S1.

\section{CONCLUSIONS}

This paper builds on the work [10]. We have improved the oversimplified campus model in [10] with one that includes a load model and a fan coil model. Historical data are used to identify and validate the model. Experimental results have been presented. The proposed Model Predictive Controller (MPC) has optimized the scheduling and operation of the central plant to achieve lower electricity cost and better efficiency.

Two main conclusions can be drawn from the experiments. Our study has enabled a $11.9 \%$ improvement of the plant Coefficient of Performance (COP) and $\$ 1205$ daily electricity bill saving. The actual tests with the MPC in feedback loop have provided a 1.5\% COP improvement. The small $1.5 \%$ reduction in COP is related to a coarse sampling of the MPC scheme. Also, the scheme has been used to confirm that some of the control profiles chosen by the operators and plant manager are very close to the optimal solution.
Ongoing research is trying to improve models, increase MPC sampling time while maintain real-time feasibility [11], and consider additional degrees of freedom such as night air ventilation in the campus buildings.

\section{ACKNOWLEDGMENTS}

This work was partially supported by the Department of Energy and Laurence Berkeley National Laboratories and NSF CAREER Award CMMI-0844456. We thank John Elliott, Satish Narayanan and Stella M. Oggianu for constructive and fruitful discussions on the system modeling and control implications.

\section{REFERENCES}

[1] B. Coffey, P. Haves, B. Hencey, M. Wetter, F. Borrelli, and Y. Ma. A semi-empirical heat exchange model for return temperature and flow rate prediction in a campus chilled water system. Technical report, Lawrence Berkeley National Lavoratory, Jan. 2010. http://www.mpc.berkeley.edu/people/ yudong-ma/files/ASHRAEcoilmodeldraftv1-dec28. pdf?attredirect $s=0$.

[2] D.B. Crawley, L.K. Lawrie, F.C. Winkelmann, W.F. Buhl, Y.J. Huang, C.O. Pedersen, R.K. Strand, R.J. Liesen, D.E. Fisher, M.J. Witte, and J. Glazer. Energyplus: creating a new-generation building energy simulation program. Energy and Buildings, 33(4):319 - 331, 2001.

[3] M. Gwerder, B. Lehmann, J. Tödtli, V. Dorer, and F. Renggli. Control of thermally-activated building systems (TABS). Applied Energy, 85(7):565 - 581, 2008.

[4] G.P. Henze, C. Felsmann, and G. Knabe. Evaluation of optimal control for active and passive building thermal storage. International Journal of Thermal Sciences, 43(2):173 - 183, 2004.

[5] G.P. Henze, M. Krarti, and M.J. Brandemuehl. Guidelines for improved performance of ice storage systems. Energy and Buildings, 35(2): $111-127,2003$.

[6] G.P. Henze, J. Pfafferott, S. Herkel, and C. Felsmann. Impact of adaptive comfort criteria and heat waves on optimal building thermal mass control. Energy and Buildings, 39(2):221 - 235, 2007.

[7] M. Koschenz and V. Dorer. Interaction of an air system with concrete core conditioning. Energy and Buildings, 30(2):139 - 145, 1999.

[8] M. Koschenz and B. Lehmann. Development of a thermally activated ceiling panel with pcm for application in lightweight and retrofitted buildings. Energy and Buildings, 36(6):567 - 578, 2004.

[9] S. Liu and G.P. Henze. Experimental analysis of simulated reinforcement learning control for active and passive building thermal storage inventory: Part 1. theoretical foundation. Energy and Buildings, 38(2):142 - 147, 2006

[10] Y. Ma, F. Borrelli, B. Hencey, A. Packard, and S. Bortoff. Model predictive control of thermal energy storage in building cooling systems. Decision and Control, 2009 held jointly with the 2009 28th Chinese Control Conference. CDC/CCC 2009. Proceedings of the 48th IEEE Conference on, pages $392-397$, dec. 2009.

[11] Y. Ma, F. Borrelli, B. Hencey, A. Packard, and S. Bortoff. Model predictive control of thermal energy storage in building cooling systems. Technical report, University of California at Berkeley, Sep. 2009. http://www.mpc.berkeley.edu/ site/mpclaboratory/people/yudong-ma/files/ YudongMa-CDC09.pdf?attredirect $s=0$.

[12] J.M. McQuade. A system approach to high performance buildings. Technical report, United Technologies Corporation, Feb. 2009. http://gop.science.house.gov/Media/ hearings/energy09/april28/mcquade.pdf.

Work was also supported by the U.S. Department of Energy under Contract No. DE-AC02-05CH11231. 